\begin{abstract}
Inclusive education has become a corner stone of many government policies in an increasing number of countries, yet teachers have been found to hold mixed attitudes towards its implementation and usefulness. This paper, using English terminology and thinking, aimed to extend previous research on the effect of teacher attitudes towards inclusion in classroom learning environments, and to explore perceived adequacy of support, levels of stress, and willingness to include pupils with certain difficulties. Teachers $(\mathrm{N}=95)$ completed questionnaires on attitudes to inclusion, classroom learning environment, support, and stress. Pupils $(\mathrm{N}=2,514)$ completed a questionnaire on classroom learning environment only. Teacher attitudes towards including SEN pupils in mainstream settings were found to have a significant impact on how they managed their classroom learning environments and how adequately they perceived available support. Teachers with more positive attitudes towards inclusion were reported by their pupils to have classroom environments with greater levels of 'satisfaction' and 'cohesiveness', and lower levels of 'friction', 'competitiveness' and 'difficulty' than for those with teachers who held less positive attitudes. Teacher attitudes towards inclusion increased with greater perceived adequacy of both internal and external support. Teachers were less willing to include pupils with behavioural difficulties than pupils who were able/gifted or had physical difficulties, irrespective of attitude to inclusion.
\end{abstract}


The active implementation of inclusive educational initiatives and practices has been supported through government policies around the world (e.g., DfES, 2001; DCSF, 2010; Peters, 2004; UNESCO, 1994). The UNESCO Salamanca conference held in 1994 had representatives from 92 governments and 25 international organisations who considered both the policy and practice shifts necessary to promote inclusive education (UNESCO, 2009). These initiatives stemmed from an increasing view that wherever possible children and young people with Special Educational Needs (SEN) (also known as Additional Support Needs (ASN), Learning Difficulties (LD), or Special Needs (SN)) should have access to mainstream schooling and the opportunities that this provides to enable them to fully participate in the wider society (Frederickson \& Cline, 2009; Janney \& Snell, 2006). A child is defined as having special educational needs if they have 'a learning difficulty which calls for special educational provision to be made' for them (Education Act, 1996, Section 312).

Schooling in the English speaking world for children and young people with SEN has shifted greatly since the 1960's, initially segregating such children through placement in separate special schools, and later moving towards integration in units attached to mainstream school sites. This meant that children and young people with SEN were placed within mainstream schools, but no changes were made to accommodate them and they were often provided with insufficient support to ensure their full participation in the wider school community (Polat, 2011). More recently, the child's full participation in school and class activities has been considered crucial to their perception of themselves as being real members of that community (Janney \& Snell, 2006).

'Inclusion' requires the child to be not only physically present within mainstream schools, but that changes to values, attitudes, policies and practices are made to ensure the pupils are able to be full participants in the class (Polat, 2011). 
The current study investigated whether classroom learning environments in mainstream primary/elementary schools were 'adaptive' for pupils with SEN in terms of levels of cohesiveness, satisfaction, friction, difficulty and competitiveness. The study aimed to assess whether these factors differed according to teachers' espoused attitudes towards including pupils with SEN in their classrooms.

The then Department for Children Schools and Families (2010) in the United Kingdom evaluated the initiative to improve the teacher workforce in relation to children and young people with SEN, which started in December 2008. Baseline findings indicated that one-third of all teachers were not actively or regularly implementing resources to support inclusive practice. This finding could be attributed to the conflicting messages given to teachers - that of raising pupil attainment whilst at the same time addressing diverse educational needs in the mainstream classroom (Jordan, Glenn \& McGhie-Richmond, 2010). This tension is particularly acute in relation to disruptive pupils (Grieve, 2009; Goodman \& Burton, 2010).

\section{Teacher Attitudes}

The success or failure of implementing inclusive educational policy and practice is dependent upon what the classroom teacher believes about such initiatives (e.g. teachers' attitudes, Forlin, Keen \& Barrett, 2008). In addition, the then Department for Education and Skills (2004) in the UK argued that successful inclusive education is determined by how well the school manages its own resources, including both internal and external support staff.

Teachers need a strong personal commitment towards inclusive practice for this intervention to be successful, with attitude affecting both teaching approach and the type of classroom learning environment created (Grieve, 2009; Ross-Hill, 2009). Ryan (2009) advocated that teachers who embraced personal responsibility and who were receptive to the notion of inclusion were more likely to adapt their classroom learning environment to meet the needs of a range of pupils through varied teaching approaches, high quality and effective 
instruction, regular monitoring of progress and focused teacher and parent/carer collaboration.

However, not all teachers embrace positive attitudes towards the inclusion of children and young people with SEN. Cook, Cameron and Tankersley (2007) found that teachers were more rejecting and less attached to included SEN children and young people, whilst at the same time expressing greater general concern for them. Although this concern could lead to increased effort to provide for their complex needs, attitudes of rejection and being less attached may paradoxically lead such teachers to be less proactive in effectively supporting them.

Grieve (2009) identified three groups of teachers: those willing to implement inclusion given that additional adequate support was available; those who considered inclusion to be detrimental to pupils without such difficulties in the class; and those who felt that pupils with social, emotional and/or behavioural difficulties required 'higher quality support than mainstream schools could offer' (Grieve, 2009: 175). These attitudes are likely to influence whether or not the child or young person with SEN is successfully included within a mainstream classroom rather than merely being located within it.

Forlin, Keen and Barrett (2008) found greater implementation of inclusion amongst younger and less experienced teaching staff, with concerns about inclusion increasing with age and number of years teaching experience. Teachers who worked with younger children expressed greater concern about implementing inclusion than those teaching older year groups (Forlin et al., 2008). This finding is contrary to that of other research which found that teachers were generally positive towards and felt confident about including SEN children and young people in their classrooms irrespective of years of teaching experience or age group taught (Ross-Hill, 2009). 


\section{Training and support}

Successful inclusive practice requires collaboration between the class teacher and the wider school community, including support and specialist staff (e.g., Educational Psychologists, Specialist Teachers and so on), as well as parents/carers (Broderick, MehtaParekh \& Reid, 2005; Janney and Snell, 2006; Vakil, Welton, O’Connor \& Kline, 2008). Teachers require knowledge, understanding and skills (and access to resources, including specialist staff) to work with the diversity of pupils found in inclusive classrooms (Hodkinson, 2009). However, Grieve (2009) and Goodman and Burton (2010) found that teachers reported insufficient training and practical support, and lacked access to information required to enable them to feel confident in implementing inclusive practices. The current study considered whether perceived adequacy of support has an impact on whether a teacher holds a positive or negative attitude towards the practice of inclusion.

\section{Inclusion in the classroom}

The inclusion of SEN pupils within mainstream school settings can best be achieved through shared learning environments and an inclusive school and community culture (Janney \& Snell, 2006). This includes teachers adapting work and goals for the pupil according to their unique 'strengths' and 'weaknesses' in such a way that they are involved in the learning, social and emotional flow of the classroom (e.g., making changes to the physical environment and using additional resources to aid SEN pupils in their learning and participation in class activities, Janney \& Snell, 2006). Broderick, Mehta-Parekh and Reid (2005: 197) suggested that 'good teachers are responsive to all learners' needs...in the sense that they prepare from the outset for a wide variety of aptitudes, needs and interests'. Pupil progress should be identified against individually focused targets rather than comparing the children with the rest of the class (Gibb, Tunbridge, Chua, \& Frederickson, 2007). 


\section{Explanation for the Current Study}

Monsen and Frederickson (2004) explored in a New Zealand study the relationship between teachers' views on inclusion and their classroom learning environments (note that the term 'inclusion' was not used in their study, but the earlier term of 'mainstreaming'). They found significant differences in the classroom learning environments created by teachers with 'positive' and 'negative' attitudes towards inclusion. The current study replicated and extended Monsen and Frederickson's (2004) original study using a large English sample.

The research questions posed were:

1. Do teachers whose attitudes to inclusion are 'high', 'medium' and 'low' as measured on a scale of positivity differ in terms of age, gender, teaching experience, class level taught, qualifications, or attendance at special education courses?

2. Do the characteristics of classroom learning environments (e.g., cohesiveness, friction, satisfaction, difficulty and competitiveness) differ between teachers whose attitudes are 'high', 'medium' or 'low'?

3. Is there a relationship between teachers' attitudes towards inclusion and their perceived adequacy of support or level of stress?

4. What types of SEN are teachers willing/unwilling to include within mainstream classrooms?

\section{Method}

\section{Participants}

One-hundred and twenty schools, with between 200 and 400 students at each, were randomly selected from the South East of England. From the questionnaires sent out to schools, 106 teachers responded with data for 2,566 pupils. Data for eleven teachers and their 
pupils was discarded due to incomplete responses from teachers or no data available for their pupils. A sample of 95 teachers (21 males; 73 females; 1 undisclosed) remained, with data for 2,514 pupils aged between seven and ten years (e.g., primary/elementary level). Class sizes ranged from 10 to 35 pupils, with a mean of 29 pupils per class.

\section{Measures}

Demographics: Background information was collected on teacher age, gender, years of teaching experience, qualifications, special education courses attended, age group taught, class size, and contact with SEN children and young people.

Teacher Attitude to Inclusion Scale (TAIS) : Larrivee and Cook's (1979) Opinions Relative to Mainstreaming (ORM) questionnaire was adapted by Monsen and Frederickson (2004) for use in their study of NZ teachers (Teacher Attitude to Mainstreaming (TAM) Scale). This measure was updated and used in the current study to measure teacher attitudes towards including SEN pupils within regular classrooms, although remained conceptually the same as the TAM. Modifications were made to the ORM / TAM, including adapting American spellings and wording, and implementing an 8-point rather than 5-point Likert-type scale (ranging from 'strongly agree' to 'strongly disagree') for consistency with the other questionnaires used in the current study. The TAIS has 30 items and like Larrivee and Cook's (1979) and Monsen and Frederickson's (2004) questionnaires, answers were arranged to control for item response bias so that 'agree' represented a positive attitude towards inclusion for 12 items and a negative attitude for the remaining 18 items.

The items were coded so that a higher score represented a more positive attitude and a lower score represented a more negative attitude towards inclusion. Total scores for the TAIS scale were used for analysis and ranged from a minimum of 30 to a maximum of 240 . The TAIS had a split half reliability coefficient of .93. 
Willingness to Include: The 'Willingness to Include' questionnaire comprised nine SEN difficulties divided into mild, moderate and severe needs. These difficulties were selected according to research on both normative and non-normative categories, taking into consideration current terminology use within the schools sampled. Difficulties included in this study were visual, hearing, behavioural, emotional, physical, learning, speech, multiple difficulties, and able/gifted children. Teachers rated their willingness to include children and young people with each difficulty across an 8-point Likert-type scale. The 'Willingness to Include' questionnaire had a split-half reliability of .92.

Adequacy of Support: The 'Adequacy of Support' questionnaire comprised 13 items in which teachers were asked to rate the perceived adequacy of support available to them across an 8-point Likert-type scale, including external support (e.g., Educational Psychologists, Speech and Language Therapists and so on), internal support from colleagues and classroom assistants, and classroom support from parent/carer helpers. This questionnaire had a splithalf reliability of .95 .

Health/Stress: The 'Health/Stress' questionnaire was based on Galloway's (reprinted in Hill \& Parsons, 2000) Scale of Teacher Stress and consisted of 12 items in which teachers were asked to rate statements regarding stress symptoms on a 4-point Likert-type scale. Lower scores indicated that teachers perceived 'a lot of stress', whereas higher scores indicated perceptions of 'little stress'. The 'Health/Stress' questionnaire had a split-half reliability of 87 .

The My Class Inventory (MCI) - Short Form: The MCI (Fraser et al., 1982; Frederickson \& Monsen, 1999; Majeed, Fraser \& Aldridge, 2002) contained five of the original fifteen scales of the Learning Environment Inventory (LEI), with language simplified for the younger target age, and the four-point scale reduced to a 2-point yes/no scale. Both teachers 
and their pupils responded to the 25 statements about the classroom learning environment across five scales:

- Cohesiveness - Extent to which students know, help, and are friendly toward each other

- Friction - Amount of tension and quarrelling amongst students

- Satisfaction - Extent of enjoyment of class work

- Difficulty - Extent to which students find difficulty with the work of the class

- Competitiveness - Emphasis on students competing with each other (Fraser et al., 1982: 5)

Fraser et al. (1982) reported satisfactory internal consistency for each scale $(0.73-0.88$ according to class means).

\section{Procedure}

A list of primary schools across the South East of England was generated, and a random sample was selected according to every $10^{\text {th }}$ school on the list. An initial telephone call was made to each school, and where they were unable to take part, the $11^{\text {th }}$ school on the list was approached instead to ensure a sample of 120 schools. Ethical approval was gained for this study through the Local Authorities (LA) in which the schools were located. Following written consent from schools, teachers, and the children's parents/carers, packs of child and teacher questionnaires were distributed for completion by each class in the school (class years 1 to 6). Teachers were asked to administer the MCI (Fraser et al., 1982) to each other's classes so as to avoid any confounding social desirability effects. To ensure that teachers and pupils had spent a sufficient length of the school year together, questionnaires were administered seven to eight months after the start of the academic year. 


\section{Results}

\section{Demographics}

Prior to analysis teachers were split into three groups: 'high' (top $25^{\text {th }}$ percentile), 'medium' (between $25^{\text {th }}$ and $75^{\text {th }}$ percentile) or 'low' (bottom $25^{\text {th }}$ percentile) attitude towards inclusion scores. Demographic information collected from teachers is presented in Table 1. For continuously-distributed variables, one-way between-groups analyses of variance (ANOVA) were conducted. No significant differences were found between teachers scoring 'high' $(\mathrm{M}=176.54, \mathrm{SD}=16.20)$, 'medium' $(\mathrm{M}=144.96, \mathrm{SD}=10.02)$, and 'low' $(\mathrm{M}=$ $101.38, \mathrm{SD}=20.56)$ on attitude scores in terms of length of teaching experience, size of class, or age level taught.

There was a significant difference in age of teacher between those with 'high' and 'low' attitude scores represented by a large effect size (as defined by Cohen, 1992), F(2,87) = $5.96, \mathrm{p}<.01, \mathrm{~d}=0.97$, but no significant differences between the 'medium' attitude scores and 'high' or 'low' scores $(\mathrm{p}>.05)$. Tukey's HSD post-hoc test was used to determine the location of this difference, which revealed that teachers with 'high' attitude scores were significantly younger $(M=35.85$ years $)$ than teachers with 'low' attitude scores $(M=45.50$ years).

Categorical variables were analysed using chi-squared. No significant differences were found for gender or special education courses attended $(p>.05)$. Analysis could not be conducted on the variables 'contact with people who have disabilities' and 'teacher qualifications' since the assumption of a minimum expected frequency of 5 was violated. 
Table 1: Descriptive statistics and ANOVA results for differences between teachers with high, medium and low scores on the Teacher Attitude to Inclusion Scale on teacher background variables

\begin{tabular}{|c|c|c|c|c|c|c|c|c|}
\hline \multirow[t]{3}{*}{ Variable } & \multicolumn{6}{|c|}{ Teacher Group } & \multicolumn{2}{|c|}{ Difference } \\
\hline & \multicolumn{2}{|c|}{$\operatorname{High}(n=24)$} & \multicolumn{2}{|c|}{$\begin{array}{l}\text { Medium } \\
(\mathrm{n}=45)\end{array}$} & \multicolumn{2}{|c|}{ Low $(n=26)$} & \multirow[t]{2}{*}{$\mathrm{F}_{(2,89)}$} & \multirow[t]{2}{*}{$\mathrm{p}$} \\
\hline & M & SD & M & SD & M & $\mathrm{SD}$ & & \\
\hline $\begin{array}{l}\text { Teaching experience } \\
\text { (years) }\end{array}$ & 10.04 & 9.07 & 11.02 & 9.70 & 15.95 & 11.27 & 2.44 & .094 \\
\hline $\begin{array}{l}\text { Age of teacher } \\
\quad \text { (years) }\end{array}$ & $35.85_{\mathrm{a}}$ & 10.03 & 40.29 & 9.32 & $45.50_{b}$ & 9.83 & 5.96 & $.004 * *$ \\
\hline Class level taught & 4.08 & 1.26 & 4.38 & 1.25 & 4.10 & 1.48 & $\begin{array}{c}0.56 \\
7\end{array}$ & .569 \\
\hline \multirow[t]{2}{*}{ Class size } & 28.81 & 3.76 & 28.77 & 4.41 & 27.90 & 3.45 & $\begin{array}{c}0.43 \\
4\end{array}$ & .649 \\
\hline & \multicolumn{2}{|c|}{ Number (\%) } & \multicolumn{2}{|c|}{ Number (\%) } & \multicolumn{2}{|c|}{ Number (\%) } & $\chi_{(2)}^{2}$ & $\mathrm{p}$ \\
\hline \multicolumn{9}{|l|}{ Gender } \\
\hline Male & \multicolumn{2}{|c|}{$4(17 \%)$} & \multicolumn{2}{|c|}{$13(29 \%)$} & \multicolumn{2}{|c|}{$4(15 \%)$} & 2.16 & .339 \\
\hline Female & \multicolumn{2}{|c|}{$19(83 \%)$} & \multicolumn{2}{|c|}{$32(71 \%)$} & \multicolumn{2}{|c|}{$22(85 \%)$} & & \\
\hline \multicolumn{9}{|l|}{ Contact with SEN } \\
\hline Yes (in class) & \multicolumn{2}{|c|}{$24(100 \%)$} & \multicolumn{2}{|c|}{$44(98 \%)$} & \multicolumn{2}{|c|}{$25(100 \%)$} & \multirow{3}{*}{\multicolumn{2}{|c|}{ N/A }} \\
\hline Yes (relative) & 0 & & & & 0 & & & \\
\hline No & $0(($ & & & & 0( & & & \\
\hline \multicolumn{9}{|l|}{ Qualification } \\
\hline $\begin{array}{l}\text { Teacher's } \\
\text { Certificate }\end{array}$ & \multicolumn{2}{|c|}{$5(24 \%)$} & \multicolumn{2}{|c|}{$9(21 \%)$} & \multicolumn{2}{|c|}{$8(32 \%)$} & N/A & \\
\hline PGCE & \multicolumn{2}{|c|}{$3(14 \%)$} & \multicolumn{2}{|c|}{$13(30 \%)$} & \multicolumn{2}{|c|}{$7(28 \%)$} & & \\
\hline University degree & \multicolumn{2}{|c|}{$8(38 \%)$} & \multicolumn{2}{|c|}{$19(44 \%)$} & 10( & $\%)$ & & \\
\hline $\begin{array}{l}\text { Studying for } \\
\text { degree/diploma }\end{array}$ & $1(5$ & & & & 0( & & & \\
\hline Other & $4(1$ & & & & 0( & & & \\
\hline Special courses & & & & & & & & \\
\hline Yes & 16( & $3 \%)$ & 19 & $\%)$ & 17 & $1 \%)$ & 5.38 & .68 \\
\hline No & $6(2$ & $\%)$ & 20 & $\%)$ & 6 & $\%)$ & & \\
\hline
\end{tabular}

Note. Means in the same row that do not share subscripts differ at $p<.01$

\section{Attitude scores and $\mathrm{MCl}$ scores}

To investigate whether teachers with more positive attitudes towards inclusion (as indicated by a 'high' score on the TAIS) organise classrooms which are perceived to be more adaptable for SEN pupils, a series of one-way between-groups ANOVAs were conducted 
based on pupils' MCI ratings of their classroom (see Table 2). Teachers with 'high' scores were expected to be more likely than 'low' scorers to provide classroom environments higher on satisfaction and cohesiveness and lower on friction, competitiveness and difficulty (Monsen \& Frederickson, 2004).

Table 2: ANOVA results for differences on child MCI scores for teachers with high, medium and low scores on the Teacher Attitudes to Inclusion Scale

\begin{tabular}{|c|c|c|c|c|c|c|c|c|}
\hline \multirow[t]{3}{*}{ MCI Scale } & \multicolumn{6}{|c|}{ Teacher Group } & \multicolumn{2}{|c|}{ Difference } \\
\hline & \multicolumn{2}{|c|}{$\operatorname{High}(n=24)$} & \multicolumn{2}{|c|}{ Medium $(n=45)$} & \multicolumn{2}{|c|}{ Low $(n=26)$} & \multirow[t]{2}{*}{$F_{(2,89)}$} & \multirow[t]{2}{*}{$\mathrm{p}$} \\
\hline & $\mathrm{M}$ & SD & $\mathrm{M}$ & SD & M & SD & & \\
\hline Satisfaction & $12.38_{\mathrm{a}}$ & 2.57 & $12.19_{b}$ & 2.57 & $11.90_{\mathrm{b}}$ & 2.66 & 5.62 & $.004 * *$ \\
\hline Friction & $9.65_{a}$ & 3.12 & $9.51_{b}$ & 3.05 & $10.35 \mathrm{~b}$ & 3.12 & 15.58 & $.000 * * *$ \\
\hline Competitiveness & $11.31_{\mathrm{a}}$ & 3.05 & $11.48 \mathrm{~b}$ & 2.95 & $12.16_{b}$ & 2.79 & 15.22 & $.000 * * *$ \\
\hline Difficulty & $7.23 \mathrm{a}$ & 2.41 & $7.55_{b}$ & 2.50 & $7.60_{b}$ & 2.52 & 4.57 & $.010 * *$ \\
\hline Cohesiveness & $10.38 \mathrm{a}$ & 3.38 & $10.20 \mathrm{~b}$ & 3.28 & $9.90_{b}$ & 3.26 & 3.48 & $.031 *$ \\
\hline
\end{tabular}

Note. Means in the same row that do not share subscripts differ significantly, ${ }^{*} \mathrm{p}<.05$, $* * \mathrm{p}<$ $.01, * * * \mathrm{p}<0.001$

The results of the ANOVA showed significant differences between teachers with 'high', 'medium' and 'low' attitude scores for each of the MCI scales: Satisfaction, F(2, $2511)=5.62, \mathrm{p}<.01 ;$ Friction, $\mathrm{F}(2,2511)=15.58, \mathrm{p}<.001 ;$ Competitiveness, $\mathrm{F}(2,2511)=$ 15.22, $\mathrm{p}<.001$; Difficulty, $\mathrm{F}(2,2511)=4.57, \mathrm{p}<.01$; and Cohesiveness, $\mathrm{F}(2,2511)=3.48, \mathrm{p}$ $<.05$

Planned comparisons of the group means indicated that when the teacher had a positive attitude to inclusion (a 'high' attitude score), pupils reported significantly greater levels of satisfaction, $\mathrm{t}(2511)=2.83, \mathrm{p}<.01$; greater cohesiveness, $\mathrm{t}(2511)=2.20, \mathrm{p}<.05$; less friction, $\mathrm{t}(2511)=-1.97, \mathrm{p}<.05$; less competitiveness, $\mathrm{t}(2511)=-3.79, \mathrm{p}<.001 ;$ and less difficulty, $\mathrm{t}(2511)=-3.02, \mathrm{p}<.01$, in comparison to 'low' or 'medium' scorers. 
Differences were seen between 'low' and 'medium' attitude scorers for satisfaction, $\mathrm{t}(2511)=2.27, \mathrm{p}<.05 ;$ friction, $\mathrm{t}(2511)=-5.49, \mathrm{p}<.001 ;$ and competitiveness, $\mathrm{t}(2511)=$ $-4.61, \mathrm{p}<.01$. There were no significant differences between 'low' and 'medium' attitude scorers for cohesiveness or difficulty $(\mathrm{p}>.05)$. Effect sizes were calculated for the significant results. According to Cohen's (1992) criteria, these revealed small effect sizes for differences between teachers with 'high' and 'low' attitude scores on scales of satisfaction $(d=0.18)$, friction $(d=0.22)$, competitiveness $(d=0.29)$, difficulty $(d=0.15)$ and cohesiveness $(d=$ $0.14)$.

Teacher ratings on the MCI revealed significant differences between teachers with 'high' and 'low' attitude scores for satisfaction, $\mathrm{F}(2,69)=3.81, \mathrm{p}<.05, \mathrm{~d}=0.87$, and for friction, $\mathrm{F}(2,69)=3.73, \mathrm{p}<.05, \mathrm{~d}=.84$, (see Table 3), each representing a large effect. The Tukey HSD post hoc test revealed that teachers with 'high' attitude scores reported greater levels of satisfaction $(p<.05)$ and less friction $(p<.05)$ in their classroom than teachers with 'low' attitude scores.

Table 3: ANOVA results for differences on teacher MCI scores for teachers with high, medium and low scores on the Teacher Attitudes to Inclusion Scale

\begin{tabular}{|c|c|c|c|c|c|c|c|c|}
\hline \multirow[t]{3}{*}{ Teacher MCI Scale } & \multicolumn{6}{|c|}{ Teacher Group } & \multicolumn{2}{|c|}{ Difference } \\
\hline & \multicolumn{2}{|c|}{$\operatorname{High}(\mathrm{n}=18)$} & \multicolumn{2}{|c|}{ Medium $(n=36)$} & \multicolumn{2}{|c|}{ Low $(n=18)$} & \multirow[t]{2}{*}{$\mathrm{F}_{(2,69)}$} & \multirow[t]{2}{*}{$\mathrm{p}$} \\
\hline & M & SD & M & SD & M & SD & & \\
\hline Satisfaction & $13.94_{a}$ & 1.21 & 13.25 & 1.73 & $12.28 \mathrm{~b}$ & 2.42 & 3.81 & $.027 *$ \\
\hline Friction & $7.44 \mathrm{a}$ & 1.85 & 8.31 & 2.04 & $9.44_{b}$ & 2.79 & 3.73 & $.029 *$ \\
\hline Competitiveness & 11.22 & 3.12 & 1.83 & 2.47 & 11.22 & 1.83 & 0.53 & .589 \\
\hline Difficulty & 7.44 & 1.82 & 7.06 & 2.11 & 7.22 & 2.82 & 0.18 & .834 \\
\hline Cohesiveness & 10.33 & 2.82 & 9.56 & 2.73 & 9.17 & 2.68 & 0.86 & .428 \\
\hline
\end{tabular}

Note. Means in the same row that do not share subscripts differ at $p<.05$ 


\section{Adequacy of Support and Stress}

A hierarchical multiple regression analysis was conducted to test whether there was a relationship between perceived adequacy of support and/or stress and teacher attitudes towards inclusion. The first block used the predictor 'adequacy of support' and the predictor 'stress' was placed in the second block. Results of Model 1 showed that 'adequacy of support' was correlated with teacher attitude towards inclusion $(\mathrm{R}=.35)$, and accounted for $12 \%$ of the variance in teacher attitude towards inclusion according to the adjusted $\mathrm{R}^{2}$ statistic. The ANOVA revealed this to be a significant amount of variance, $F(1,53)=7.56$, $p$ $<.01$. Including 'stress' within Model 2 did not significantly increase the amount of variance accounted for by teacher attitudes ( $\mathrm{p}>.05)$, suggesting that teachers' perception of stress is not related to attitudes towards inclusion.

Table 4: Multiple regression analysis results for the relationship between adequacy of support and/or stress and teacher attitudes towards inclusion

B $\quad$ SE B $\quad \beta$

Step 1

$\begin{array}{llll}\text { Constant } & 0.99 & 0.37 & \\ \begin{array}{l}\text { Adequacy of } \\ \text { support }\end{array} & 0.02 & 0.01 & .35^{* *}\end{array}$

Step 2

Constant

$0.51 \quad 0.56$

Adequacy of

0.02

0.01 $.33^{*}$

support

\begin{tabular}{cll} 
Stress & 0.02 & 0.01 \\
\hline Note $\mathrm{R}^{2}=.125$ for Step $1 ;$ & $\mathrm{R}^{2}=.021$ for Step 2. * $\mathrm{p}<.02 ; * * \mathrm{p}<.01$
\end{tabular}

\section{Willingness to include children and young people with difficulties}

A one-way repeated measures ANOVA was conducted to investigate whether there were any significant differences in the type of difficulty that teachers with 'low', 'medium' 
and 'high' attitudes towards inclusion were willing to include or exclude in their classroom. Mauchly's test indicated that the assumption of sphericity was violated for teachers with 'low', $\chi^{2}(35)=0.02, \mathrm{p}<.001$; 'medium', $\chi^{2}(35)=0.02, \mathrm{p}<.001$; and 'high', $\chi^{2}(35)=0.05, \mathrm{p}$ $<.01$ attitudes towards inclusion and so the degrees of freedom were corrected using Greenhouse-Geisser (Low: $\varepsilon=.52$; Medium: $\varepsilon=.49$; High: $\varepsilon=.59$ ).

The results of the repeated measures ANOVA for teachers with a 'low' attitude score indicated a significant difference between teachers' willingness to include a range of pupils presenting difficulties within their classroom, $\mathrm{F}(4.12,87.49)=11.55, \mathrm{p}<.001$. Pair-wise comparisons were conducted using the Bonferroni adjustment. These results suggested that teachers with 'low' attitudes towards inclusion were significantly more willing to include able/gifted pupils over pupils with multiple difficulties $(\mathrm{p}<.001)$.

For teachers with a 'medium' score for attitude to inclusion, the results of the repeated measures ANOVA indicated a significant difference between teachers' willingness to include a range of children and young people presenting difficulties within their classroom, $\mathrm{F}(3.93$, $153.32)=16.89, \mathrm{p}<.001$. Pair-wise comparisons were conducted using the Bonferroni adjustment. These indicated that 'medium' attitude score teachers were significantly more willing to include pupils with visual difficulties, learning difficulties or speech and language difficulties rather than pupils with behavioural or multiple difficulties $(\mathrm{p}<.001)$. These teachers were more willing to include able/gifted pupils rather than pupils with behavioural difficulties $(\mathrm{p}<.001)$ or multiple difficulties $(\mathrm{p}<.001)$.

For teachers with a 'high' score for attitude to inclusion, the results of the repeated measures ANOVA indicated a significant difference between teachers' willingness to include a range of children and young people presenting difficulties within their classroom, F(4.76, $114.14)=9.77, \mathrm{p}<.001$. Pair-wise comparisons were conducted using the Bonferroni adjustment. These indicated that 'high' attitude score teachers were significantly more willing 
to include able/gifted pupils ( $\mathrm{p}<.001)$, pupils with learning disabilities $(\mathrm{p}<.001)$, or pupils with speech and language difficulties $(\mathrm{p}<.001)$ rather than pupils with behavioural difficulties. 'High' attitude score teachers were significantly more willing to include able/gifted pupils $(\mathrm{p}<.001)$, or pupils with learning disabilities $(\mathrm{p}<.001)$, or speech and language difficulties $(\mathrm{p}<.001)$ rather than pupils with multiple difficulties.

Table 5: Mean scores for teachers' willingness to include children with each difficulty Willingness to include Teacher Group

\begin{tabular}{|c|c|c|c|c|c|c|}
\hline & \multicolumn{2}{|c|}{ High Attitude } & \multicolumn{2}{|c|}{ Medium Attitude } & \multicolumn{2}{|c|}{ Low Attitude } \\
\hline & Mean & SD & Mean & SD & Mean & SD \\
\hline Hearing Difficulties & 18.72 & 5.25 & 19.52 & 3.63 & 14.06 & 4.71 \\
\hline Behavioural Difficulties & 16.64 & 4.65 & 15.72 & 4.65 & 10.86 & 5.19 \\
\hline Emotional Difficulties & 19.20 & 4.91 & 18.19 & 4.17 & 13.77 & 5.61 \\
\hline Physical Difficulties & 18.60 & 5.24 & 19.43 & 4.36 & 13.77 & 6.36 \\
\hline Able/Gifted & 21.84 & 3.68 & 21.14 & 2.91 & 18.00 & 7.27 \\
\hline Visual Difficulties & 19.16 & 4.90 & 20.02 & 3.32 & 13.81 & 5.14 \\
\hline Learning Difficulties & 20.60 & 4.44 & 19.88 & 3.80 & 14.23 & 5.96 \\
\hline $\begin{array}{l}\text { Speech/ Language } \\
\text { Difficulties }\end{array}$ & 20.60 & 4.16 & 19.86 & 3.87 & 14.27 & 5.96 \\
\hline Multiple Difficulties & 16.76 & 4.35 & 16.45 & 4.11 & 11.59 & 6.07 \\
\hline
\end{tabular}

\section{Discussion}

\section{Teacher differences}

The first research question addressed whether differences in teacher age, gender, years of teaching experience, class level taught, qualifications, or attendance at special education 
courses had a significant main effect on teachers' attitudes towards inclusion. The current data is consistent with findings reported by Monsen and Frederickson (2004) and Ross-Hill (2009). The study found that years of teaching experience, age level and size of class taught, gender of the teacher, or attendance on special education courses had no significant effect on teachers' attitudes towards the concept of 'inclusion'. These findings suggest that differences in attitudes towards inclusion were not associated in this sample with individual differences between teachers and the classes they taught. It seemed more likely that other factors were contributing to the development of teachers' attitudes.

Attitude of teachers was found to be significantly different according to their age, which was also found in a study by Forlin et al. (2008). Teachers with highly positive attitudes towards inclusion (as indicated by higher attitude scores) were significantly younger than those with lower attitude scores. One might assume from this finding that younger teachers are more up-to-date on training and are therefore more accepting of adopting inclusive education policies. However, the finding that 'years of teaching experience' does not have a significant impact on 'teacher attitude' suggests that the observed significant effect for age on attitude cannot be explained by teachers being recently trained and presumably more prepared for an inclusive classroom practice.

Previous research found that teachers' concerns over threats to their professional competency and integrity increased with age (Forlin et al., 2008). This could help explain why older teachers were more reluctant to include children and young people with SEN. Older teachers might prefer not to be faced with the additional challenge of children who might present difficulties within the classroom as this could reflect on their competency. This observation has potential implications for applied practice as older teachers may require slightly different and additional support to enable them to confidently adopt inclusive practices within their classrooms. Further research is needed to investigate whether perceived 
professional competence could help explain why younger teachers hold significantly more positive attitudes than older teachers.

\section{Classroom learning environment}

The second research question addressed whether the characteristics of the classroom learning environment (e.g., cohesiveness, friction, satisfaction, difficulty and competitiveness) differ between teachers whose attitudes to inclusion were 'high', 'medium' or 'low'. As in the Monsen and Frederickson's (2004) study, teachers with highly positive attitudes towards inclusion had significantly greater levels of perceived satisfaction and significantly less friction in their classroom according to child MCI ratings. Unlike Monsen and Frederickson's (2004) findings, the current study demonstrated that teachers with highly positive attitudes towards inclusion were rated by their pupils to have a significantly greater level of cohesiveness, and significantly less competitiveness and difficulty in their classroom than teachers who held low or medium attitudes. This finding may reflect the larger sample size used in the present study. This finding may suggest that teachers with highly positive attitudes towards inclusion make a greater effort to adapt their learning, social, and emotional classroom environment to reflect an atmosphere suitable for included SEN pupils (and one suitable for the learning of all children and young people). The findings from the current study suggest that whether a teacher has a positive or negative attitude towards inclusion has an impact on how they manage their classroom learning environments. This observation has implications for schools as it suggests some staff might need active assistance to develop inclusive practices which will impact positively on subsequent learning environments. Further research is required to identify exactly what teachers who hold positive attitudes do differently in their classrooms compared with others who hold less positive views towards inclusion. 
The current study found that the attitude of teachers is associated with whether or not they are willing to provide an inclusive environment for children and young people with SEN. The significant results for both the teacher and the child ratings of the classroom learning environment suggest either that teachers took responsibility for ensuring an inclusive classroom, as suggested by Ryan (2009), or that a more positive classroom environment helped the teacher to be more open to including SEN pupils in their classroom. Experimental investigation would be beneficial in future research to explore the direction of this effect, in addition to other variables which may also be influential.

\section{Adequacy of Support and Stress}

The third research question addressed whether there was a relationship between attitude towards inclusion and teachers' perceived adequacy of support or levels of stress. Findings indicated that teachers' positive attitudes towards inclusion increased according to perceived adequacy of support. Such a finding adds support to the claims made by Broderick et al. (2005) and Vakil et al. (2008) that a collaborative effort is required for successful inclusion to occur. Goodman and Burton's (2009) suggestion that the lack of support available to teachers leads to non-inclusive classroom environments and negative attitudes towards including pupils with SEN was also supported by the current findings.

These outcomes hold implications for the support available for teachers who work with SEN pupils. The findings suggest that teachers who feel inadequately supported are less likely to hold positive attitudes towards including pupils with SEN. Those with less positive attitudes are also less likely to provide classroom learning environments suitable for pupils with SEN (and all pupils). It is therefore imperative that adequate internal and external supports are made available to teachers to mediate these effects.

The findings suggest that improving the adequacy of both internal and external support services and resources for teachers could be beneficial in helping them to develop 
more positive attitudes towards including pupils with SEN, particularly where pupils have behavioural or multiple difficulties.

Findings from the current study indicated that there was no relationship between teacher attitudes towards inclusion and perceived health/stress. This finding was somewhat surprising since it was assumed that teachers who are stressed would be less willing to include children who may cause additional difficulties within their classroom. A possible limitation in exploring this variable was that the teachers in the sample did not report a large degree of stress. The mean score for teacher stress was 34.5 , which falls in the low stress level range. Further research is required using a sample of both high and low stress teachers to explore whether perceived stress has an effect on the attitude of teachers towards inclusion. In addition, there is the possibility that the effect of stress was mediated by the teachers' perceived adequacy of support or other variables. This is also an area for future research.

\section{Willingness to include}

The fourth research question addressed the types of SEN that teachers were willing or unwilling to include within mainstream classrooms. Teachers were found to have significant preferences for including certain difficulties over others. Teachers with 'high', 'medium' and 'low' attitudes towards inclusion expressed least willingness to include pupils with behavioural or multiple difficulties. This finding is consistent with previous research by Goodman and Burton (2010), who suggested that this could be explained by the anticipated increased disruption to the classroom caused by these groups of children.

Teachers had a preference to include able/gifted children and young people. This could be due to the perception that this group is less likely to be disruptive and probably easier to work with.

Considering the current research findings that teacher attitudes have a significant impact on the classroom learning environment, the issue of teachers being least willing to 
include children with behavioural or multiple difficulties holds implications for the success of inclusive education. This issue needs to be addressed so that these children and young people can be successfully included within the mainstream classroom. Future research needs to explore how to comprehensively support teachers if the inclusion of these groups is to be effective.

Finally, the current study reiterates the conclusion reached in Monsen and Frederickson's (2004) study based on their New Zealand sample that educational policy makers and those placing SEN pupils in mainstream school settings need to actively take into account the attitudes of teachers and their needs for both internal and external support (e.g. resources, including access to specialist staff, back-up and training). Failure to do so could result in a situation where the mainstream school becomes more rather than less restrictive for already vulnerable children and young people (Slee, 2008). 


\section{References}

Broderick, A., Mehta-Parekh, H., \& Reid, D.K. (2005). Differentiating instruction for disabled students in inclusive classrooms. Theory into Practice, 44(3), 194-202.

Cook, B.G., Cameron, D.L., \& Tankersley, M. (2007). Inclusive teachers' attitudinal ratings of their students with disabilities. The Journal of Special Education, 40(4), 230-238.

Department for Children, Schools and Families (DCSF) (2010). Evaluation of impact of DCSF investment in initiatives designed to improve teacher workforce skills in relation to SEN and disabilities: The first 6 months. London, UK: DCSF.

Department for Education and Skills (DfES) (2001) Inclusive schooling: Children with special educational needs. Nottingham, UK: DfES.

Department for Education and Skills (DfES) (2003). Every Child Matters. London, UK: The Stationery Office.

Department for Education and Skills (DfES) (2004). Inclusion and Pupil Achievement. Nottingham, UK: DfES.

Department for Education and Skills (DfES) (2006). Preventing Social Exclusion of Disabled Children and Their Families. Nottingham, UK: DfES.

Education Act (1996). Part IV Special educational needs, Section 312. London: HMSO

Forlin, C., Keen, M., \& Barrett, E. (2008). The concerns of mainstream teachers: Coping with inclusivity in an Australian context. International Journal of Disability, Development and Education, 55(3), 251-264.

Fraser, B.J., Anderson, G.A., \& Walberg, H.J. (1982). Assessment of learning environments: Manual for Learning Environment Inventory (LEI) and My Class Inventory (MCI). Perth, Australia: Western Australian Institute of Technology.

Frederickson, N., \& Cline, T. (2009). Special Educational Needs, Inclusion and Diversity. Second Edition. Berkshire, UK: McGraw-Hill. 
Frederickson, N. \& Monsen, J. (1999). The Learning Environment. Psychology in Education Portfolio. NFER-Nelson.

Gibb, K., Tunbridge, D., Chua, A., \& Frederickson, N. (2007). Pathways to inclusion: Moving from special school to mainstream. Educational Psychology in Practice, 23(2), 109-127.

Goodman, R.L., \& Burton, D.M. (2010). The inclusion of students with BESD in mainstream schools: teachers' experiences of and recommendations for creating a successful inclusive environment. Emotional and Behavioural Difficulties, 15(3), 223-237.

Grieve, A.M. (2009). Teachers' beliefs about inappropriate behaviour: challenging attitudes? Journal of Research in Special Educational Needs, 9(3), 173-179.

Hill, F., \& Parsons, L. (2000). Teamwork in the Management of Emotional and Behavioural Difficulties. London, UK: David Fulton.

Hodkinson, A. (2009). Pre-service teacher training and special educational needs in England 1970-2008: Is government learning the lessons of the past or is it experiencing a groundhog day? European Journal of Special Needs Education, 24(3), 277-289.

Isaksson, J., Lindqvist, R., \& Bergstrom, E. (2010). Struggling for recognition and inclusion - parents' and pupils' experiences of special support measures in school. International Journal of Qualitative Studies on Health and Well-Being, 5(1), 4646-4657.

Janney, R.E., \& Snell, M.E. (2006). Modifying schoolwork in inclusive classrooms. Theory into Practice, 45(3), 215-223.

Jordan, A., Glenn, C., \& McGhie-Richmond, D. (2010). The Supporting Effective Teaching (SET) project: The relationship of inclusive teaching practices to teachers' beliefs about disability and ability, and about their role as teachers. Teaching and Teacher Education, 26, 259-266. 
Teachers' attitudes towards inclusion

Larrivee, B. (1982). Factors underlying regular classroom teachers' attitudes to mainstreaming. Exceptional Children, 48, 34-39.

Larrivee, B., \& Cook, L. (1979). Mainstreaming: A study of the variables affecting teacher attitude. Journal of Special Education, 13(3), 315-324

Majeed, A., Fraser, B.J., \& Aldridge, J.M. (2002). Learning environment and its associations with student satisfaction among mathematics students in Brunei Darussalam. Learning Environment Research, 5, 203-226.

Monsen, J.J., \& Frederickson, N. (2004). Teachers' attitudes towards mainstreaming and their pupils' perceptions of their classroom learning environment. Learning Environments Research, 7, 129-142.

Peters, S.J. (2004). Inclusive Education: An EFA strategy for all children (Research Report No: 31195). Retrieved from World Bank Website: http://www.worldbank.org

Polat, F. (2011). Inclusion in education: A step towards social justice. International Journal of Educational Development, 31, 50-58.

Resch, J.A., Mireles, G., Benz, M.R., Grenwelge, C., Peterson, R., \& Zhang, D. (2010). Giving parents a voice: A qualitative study of the challenges experienced by parents of children with disabilities. Rehabilitation Psychology, 55(2), 139-150.

Ross-Hill, R. (2010). Teacher attitude towards inclusion practices and special needs students. Journal of Research in Special Educational Needs, 9(3), 188-198.

Ryan, T.G. (2009). Inclusive attitudes: a pre-service analysis. Journal of Research in Special Educational Needs, 9(3), 180-187.

Slee, R. (2008). Beyond special and regular schooling? An inclusive educational reform agenda. International Studies in Sociology of Education, 18(2), 99-116.

UNESCO. (1994). The Salamanca statement and framework for action on special needs education. Paris, France: UNESCO. 
Teachers' attitudes towards inclusion

UNESCO (2009). Policy Guidelines on Inclusive Education. Paris, France: UNESCO

Vakil, S., Welton, E., O’Connor, B., \& Kline, L.S. (2009). Inclusion means everyone! The role of the early childhood educator when including young children with autism in the classroom. Early Childhood Education Journal, 36, 321-326. 